\title{
Towards a culture of quality assurance in optometric education in sub-Saharan Africa
}

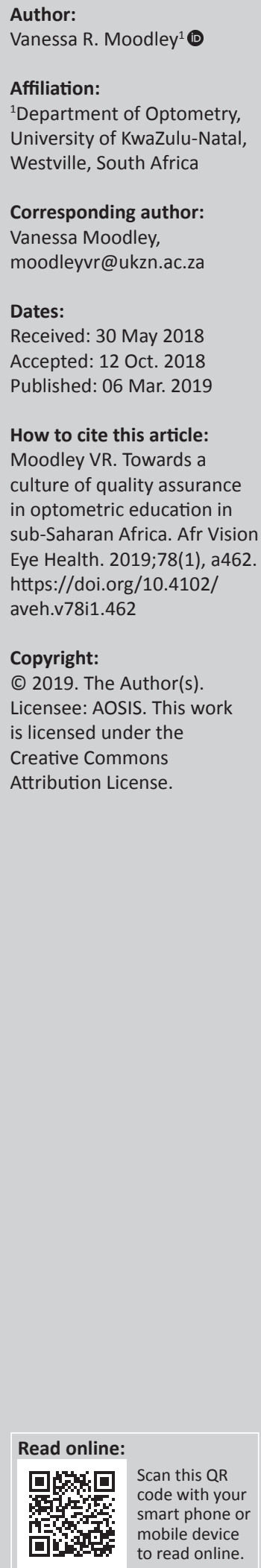

Background: New optometry education programmes in sub-Saharan Africa share a responsibility for blindness prevention by virtue of producing the countries first practitioners. Programmes need to be relevant and of a high quality to ensure sustainability. A quality culture is not a single event involving an accreditation audit but an integrated continuous system across core academic areas and accepted by all concerned in the programme.

Aim: The aim was to determine the extent to which quality assurance is integrated into the 11 participating optometry education programmes in sub-Saharan Africa.

Setting: The study was conducted in sub-Saharan Africa.

Methods: A qualitative approach, employing a phenomenological design was used in the study. Key academics in leadership were purposively selected and then consented to participate in interviews covering the core academic areas, namely, governance, recruitment and selection, teaching and learning, curriculum design, staff development, research, community-based training and student support. Transcribed data was iteratively analysed.

Results: Only one sub-Saharan country undergoes the three levels of quality audits within a regulated optometric environment. Despite a few pockets of best practices in some core areas, there was a reported general lack of quality assurance initiatives, national guidelines and adequate leadership capacity.

Conclusion: This study highlighted the absence of regulatory authorities and mandatory quality audits, which contribute to the general lack of a quality culture in optometry programmes. Schools should aim to embed a culture of quality that produces competent, socially relevant graduates and impactful research. It is recommended that schools at national, regional and global levels collaborate towards the development of a quality assurance culture across optometry education programmes in sub-Saharan Africa.

Keywords: quality assurance; optometric education; quality teaching and learning; higher education.

\section{Introduction}

The concept of quality is traced back to industry and business where, in the 20th century, issues of inspection, control and assurance of the quality became important in mechanisation. Edward Deming, Joseph Juran and Phillip Crosby were pioneers of quality in their respective fields and many of their contributions had implications for higher education. ${ }^{1}$ The United Stated (US) and Europe took the lead in the 1980s and 1990s to introduce quality assurance (QA) formally into higher education, with the momentum increasing exponentially and many other developed and developing countries following suit. , $, 3,4$ Organisations such as the World Bank, United Nations Educational, Scientific and Cultural Organization (UNESCO), Organisation for Economic Cooperation and Development, International Network for Quality Assurance Agencies in Higher Education (INQAAHE), regional organisations as well as professional associations have played significant roles in the introduction and spread of formal QA in higher education across the globe. ${ }^{5}$

The definition of QA varies according to the emphasis that the organisation wants to place on it and the context within which it relates. Highlighting the role of stakeholders, the INQAAHE states that 'assurance of quality in higher education is a process of establishing stakeholder confidence that provision (input, process and outcomes) fulfils expectations or measures up to threshold minimum requirements'. ${ }^{6}$ UNESCO, focusing on standards, defines QA as 'the systematic review of educational programs to ensure that acceptable standards of education, scholarship and infrastructure are being maintained'. This focus on standards is also echoed by the South African Council on Higher Education, Higher Education Quality Committee, ${ }^{8}$ which defines QA as the 'processes of ensuring that specified standards or requirements have been achieved'. Duff et al. ${ }^{9}$ in defining QA as 'a 
process of demonstrating excellence, accountability and value for money' highlight the responsibility of institutions to prove that they are accountable and delivering the services for which they are funded.

The multidimensional matrix of quality is emphasised in a seminal paper by Harvey and Green that focused on five key aspects, namely: ${ }^{10}$

- exception: defining quality in terms of excellence, passing a minimum set of standards

- perfection: focusing quality on the process and aiming at zero defects

- fitness for purpose: relates quality to a purpose defined by the provider

- value for money: focusing quality on efficiency and effectiveness by measuring outputs against inputs

- quality as transformation: conveys the notion of a qualitative change that enhances and empowers the students through their learning process. (p. 17-25)

The United Kingdom Higher Education Quality Assurance Agency includes students in their definition, stating that QA is 'the totality of systems, resources and information devoted to maintaining and improving the quality and standards of teaching, scholarship and research, and of student experience'. Whilst agreeing that it will constitute acceptable quality if the provision of an institution is 'fit for purpose', making effective use of resources and offering stakeholders value for money, most of these definitions focus singly on achievement of quality. Vroeijenstijn ${ }^{11}$ emphasises that continuous attention to quality by the spread of quality awareness among faculty, staff and students is the best way to ensure quality. Quality assurance is not a singleevent, dependent on measurements and instruments, but rather an ongoing, embedded institutional culture. Moloi and Motaung ${ }^{12}$ also argue that it is equally important to promote improvement, rather than mere maintenance of quality, placing a responsibility on higher education institutions to create an ongoing culture of QA that recognises the need for continual quality improvement across all sectors.

In recent years new optometry programmes have been introduced in some countries in Africa. Noting the dire state of eye care services across the continent, with most countries having few health personnel with appropriate competencies, low productivity and an uneven distribution of resources, ${ }^{13}$ these new optometry programmes share the responsibility of also improving the eye care services within their respective countries. To succeed they will need to develop and integrate systems for long-term sustainability, producing graduates who are suitably competent and possessing skills and knowledge relevant for the context within which they will work. The provision of higher education programmes of good quality within developing countries is a solution to building the capacity of the healthcare workforce in those countries. ${ }^{14}$ Integral to the development and delivery of a successful, sustainable programme is the demonstration of a high quality programme with defined policies and an embedded, explicit QA culture. This article reports on the QA practices in countries offering optometric education in sub-Saharan Africa.

\section{Methods Study design}

A qualitative approach, employing a phenomenological design was used to determine to what extent QA policies and practices were integrated into optometry education programmes in subSaharan Africa.

\section{Study participants}

Through purposive selection, key academics in optometry leadership were invited and 11 leaders from optometry schools across six sub-Saharan African countries (South Africa [5], Mozambique [1], Malawi [2], Ghana [1], Tanzania [1] and Ethiopia [1]) consented to participate in the interviews.

\section{Study process}

Subsequent to study approval and obtaining participant consent, semi-structured interviews were conducted telephonically, via Skype or face-to-face in accordance with the participant's convenience. Interviewees responded to the same set of probe questions, specifically formulated by the researcher after reviewing, synthesising and adapting existing frameworks (World Federation for Medical Education's Global Standards for Quality Improvement [2012] ${ }^{15}$, South African Professional Board for Optometry and Dispensing Opticians Accreditation Framework [HPCSA 2014] ${ }^{16}$ and the World Council for Optometry Global Scope of Practice Competency Standards Framework [WCO 2015]). ${ }^{17}$ In addition, the researcher's personal experience and opinion were applied to finalise the areas of enquiry and the set of probe questions.

The probe questions were designed to explore the extent to which QA policies and practices are employed within the core areas that constitute an academic programme, namely, governance, recruitment and selection, teaching and learning, curriculum design, staff development, research, communitybased training and student support. Each interviewee responded in relation to their respective institution's or programme's application of QA.

\section{Data management}

Data was recorded by the researcher in the form of research notes and audio recordings. Transcribed recordings and notes were collated, coded and grouped according to the major areas of enquiry in preparation for analyses. Data was then iteratively analysed to gain a clear understanding of existing QA policies and practices integrated into the different areas of the programme and current challenges. With each iteration, data was examined to reveal the gaps and, through a reflective process, recommendations towards implementation of a QA culture emerged.

\section{Ethical considerations}

This article is part of the author's PhD study, which received ethical approval from the Research Ethics Committee of the Dublin Institute of Technology, Ireland. All approved ethical standards were followed in the study. 


\section{Results}

Many sub-Saharan African institutions fall under the Higher Education Quality Councils within their respective countries (Table 1). These are usually statutory bodies, reporting to their respective Ministries of Education responsible for the QA of all higher education within the country concerned.

The three levels of QA evaluations, namely, optometry programme internal self-reviews, external programme audits by the national regulatory Professional Board for Optometry and Dispensing Opticians and institutional external reviews by the Council for Higher Education were undertaken only in South Africa. Ghana and Tanzania have national quality agencies that have conducted institutional accreditations but have not had a specific professional optometry board programme audit nor do the respective optometry programmes conduct self-evaluations. A majority of the interviewees stated that their programmes were approved by the National Medical Councils, as there are no specific optometry regulatory bodies to approve programmes or monitor quality standards. Most academic leaders raised common existing measures and threats to quality within their programmes (Table 2).

Generally, academic leaders identified the lack of formalised QA policies and practices as being a serious threat to the sustainability of the new programmes. Some evidence of specific quality initiatives undertaken were as follows:

- In response to the poor level of secondary school education plaguing South Africa, some universities introduced a foundation programme to help bridge the gap between secondary school and university. To help address access, students from academically disadvantaged secondary schools improve their results in this 1-year programme before applying for entry into the optometry programme. However, the impact on the throughput rates of these learners has yet to be determined. The programme also employs a full-time academic development officer within the optometry department specifically to provide academic and social support for students, an intervention particularly

TABLE 1: The higher education quality assurance agencies in countries represented in this study, the respective optometry regulatory bodies and the roles of the regulatory organisations in quality assurance in optometry programmes.

\begin{tabular}{llll}
\hline Country & HE quality assurance agency & Optometry regulatory body & Role in quality assurance audits and/or programme approval \\
\hline Kenya & Commission for Higher Education & None & $\begin{array}{l}\text { Programme quality audits: Not conducted. } \\
\text { New programme approvals: Programme not yet approved. }\end{array}$ \\
Tanzania & Higher Education Accreditation Council & None & $\begin{array}{l}\text { Programme quality audits: Not conducted. } \\
\text { New programme approvals: Tanzania commission for universities. }\end{array}$ \\
South Africa & Higher Education Quality Council & $\begin{array}{l}\text { Professional Board for Optometry } \\
\text { and Dispensing Opticians }\end{array}$ & $\begin{array}{l}\text { Programme quality audits: PBODO undertakes audits and sets national } \\
\text { competency standards. } \\
\text { New programme approvals: PBODO, CHE and DoHET. }\end{array}$ \\
Mozambique & $\begin{array}{l}\text { National Commission of Accreditation } \\
\text { and Evaluation of Higher Education }\end{array}$ & None & $\begin{array}{l}\text { Programme quality audits: Not conducted. } \\
\text { Eew programme approvals: Medical Council. }\end{array}$ \\
Ethiopia & $\begin{array}{l}\text { Higher Education Relevance and } \\
\text { Quality Assurance Agency }\end{array}$ & None & $\begin{array}{l}\text { Programme quality audits: Not conducted. } \\
\text { New programme approvals: Medical Council. }\end{array}$ \\
${ } }$ & National Accreditation Board & None & $\begin{array}{l}\text { Programme quality audits: Allied Health Task Force (newly formed) } \\
\text { reviews infrastructure and curriculum. } \\
\text { New programme approvals: National Accreditation Council. }\end{array}$ \\
Malawi & $\begin{array}{l}\text { National Council for Higher Education } \\
\text { (no specific QA body) }\end{array}$ & None & $\begin{array}{l}\text { Programme quality audits: Not conducted. } \\
\text { New programme approval: Medical Council. }\end{array}$ \\
\hline
\end{tabular}

HE, higher education; PBODO, Professional Board for Optometry and Dispensing Opticians; CHE, Council for Higher Education; DoHET, Department of Higher Education; QA, quality assurance

TABLE 2: Quality assurance protocols in place at discipline or institutional level and potential threats compromising quality as raised by the majority of interviewees.

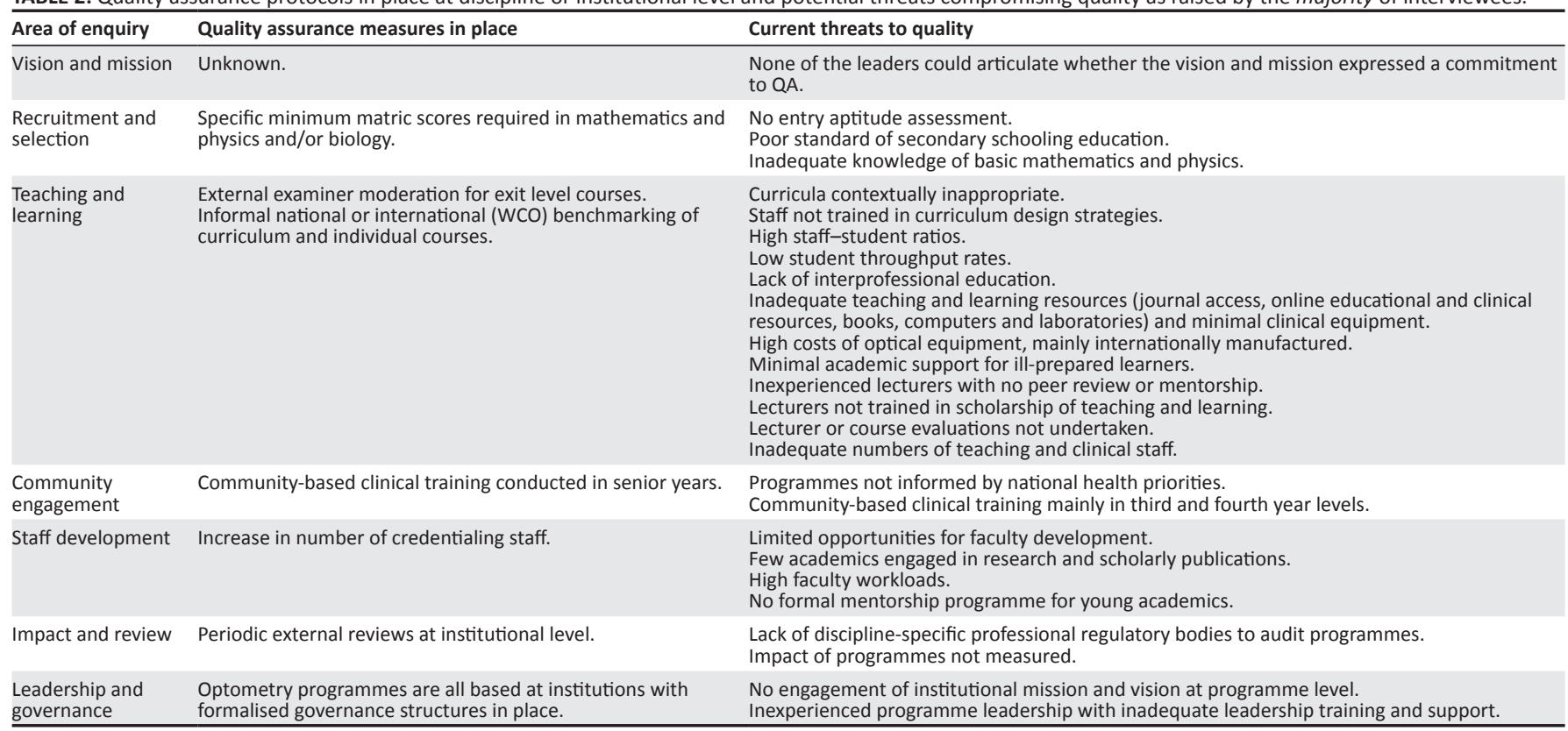

QA, quality assurance; WCO, World Council for Optometry. 
important to historically academically and socioeconomically disadvantaged learners.

- Students at Universidade Lúrio in Mozambique have a family within the community assigned to them in their early years of training, enabling them to provide health education information and to learn 'first hand' about the issues that impact on the assigned families' general and ocular health status.

- One of the heads of departments stated that:

$[L]$ ecturers generally joined directly from private practice and are allocated a course to teach. There is no specific training provided prior to them doing their first lecture, as it is presumed that if they are qualified optometrists, they should be able to teach.

Lecturers from two institutions have to complete a formal higher education qualification.

- Cape Peninsula University of Technology conducts formal impact assessments via annual input from an advisory committee made up of a variety of stakeholders.

\section{Discussion}

The most evident challenge to a quality culture in optometric education, highlighted by the majority of participating academic leadership, has been the absence of organisational regulatory bodies in optometry to define, monitor and promote quality standards. Only one participating country has programmes that undergo the three stages of QA: selfreviews, professional board audits as well as institutional accreditations. Oduntan et al. ${ }^{18}$ report that Nigeria has the tasks split, with the Nigerian Universities Council conducting institutional accreditation focusing on academic content, physical facilities, staffing, staff and student welfare, library facilities, funding, as well as employers' reports on graduates, whilst the professional and academic standards, staffing, clinical facilities, and students' clinical and practice exposure are accredited by the Optometrists and Dispensing Opticians Registration Board of Nigeria. However, the authors do not report on self-evaluations. Periodic reviews by the Medical Councils, evident in most countries, pose quality risks as most programmes are relatively new and operate without any QA framework or guideline defined by optometrists.

This lack of QA bodies in optometry is a reflection of a general historical problem in higher education in Africa, with only recently an increase in the number of new national QA bodies. ${ }^{19,20}$ However, Mohamedbhai ${ }^{21}$ claims that these are nascent bodies that face serious challenges of lack of staff, expertise and funding. This may explain the reported scenario where, apart from the respective body having approved the programme for implementation, there is very little further engagement with the new optometry programmes represented in this study. Optometry programmes should engage with their respective national departments of health and education to lobby for the formation of statutory bodies to regulate the quality of optometry programmes.

There is also a lack of published frameworks for QA in most countries offering higher education in sub-Saharan Africa. ${ }^{22}$
An evaluation framework detailing measures can serve as a guide to new programmes. In the absence of current national criteria, participating countries with developed QA frameworks for optometry could assist fellow institutions towards the introduction of a quality culture. The respective departments of optometry could start to introduce QA initiatives into their programmes. These initiatives should cover the core areas as defined in the following sections.

\section{Vision and mission}

The culture of an institution is generally reflected in its mission and vision, which should be well defined and broadly understood by all stakeholders. Ideally, the integration of a culture of QA must be reflected in the institution's vision and mission statements and be explicitly evident from the stages of recruitment and selection through to post-graduation. The lack of detailed knowledge by academic leaders of their respective institutions' vision and mission requires intervention to ensure alignment of their optometry programmes. Engaging in periodic conversations around the principles of QA, embedded within the vision and mission, will enable optometry leadership, staff and students to remain informed and contribute to the incorporation of these principles into their respective departments.

\section{Recruitment and selection}

As a means of addressing the low throughput rates widely reported, programmes could carefully craft admission and selection criteria to admit students with the required aptitude and potential to cope with the rigour of the optometry programme. The reported poor level of secondary school education, especially in mathematics and physics, can be addressed by students being supported before they formally enter the optometry programme. The bridging programme offered at some institutions could be considered for wider adoption to help prepare academically disadvantaged students and create access into optometric education. In the context of increasing access to eye care services rural students may be recruited and supported successfully as evidenced in the North Ontario School of Medicine, which successfully recruited applicants from underserved areas and reported signs of graduates being produced with skills appropriate to rural health. ${ }^{23}$ They further claim that their recruitment programme has been successful, without lowing standards, with their graduates achieving above-average scores in national examinations.

A second layer of selection to ensure admission of applicants with the appropriate skill sets, aptitude, attitude and passion for optometry is for an aptitude test to be implemented that potentially may help to identify students with requisite potential to be successful. The Optometry Admission Test, administered by the Association of Schools and Colleges of Optometry in the US (ASCO n.d.) $)^{24}$, is an example of an admission test designed to measure general academic ability and comprehension of scientific information. However, it is important for the test to be contextually relevant and to assess, 
in addition to scholastic ability, other areas such as attitudes and interest as included in the validated Assessment of Interest in Medicine and Science survey. ${ }^{25}$ Individual countries may develop their own tests or, ideally, an opportunity exists for schools on the continent to collectively develop a contextually relevant African optometry admission test.

\section{Curriculum}

Prior to defining QA protocols for the delivery of the curriculum, the design has to meet the acceptable quality standards and be relevant to local contexts. Strasser et al. ${ }^{26}$ define a community consultative process that produced a holistic curriculum grounded in the health context. Their model has a strong emphasis on interprofessional education with the patient and family being central to learning and providing students with experience in diversity of cultures. Although the World Council for Optometry's global competency framework was cited as the basis for curricula at most of the represented institutions, it was acknowledged that, to be appropriate, it will need to be adapted to be locally relevant. Broad stakeholder (professional associations, students, alumni, government health departments, private employers and community organisations) consultations could be conducted for input and feedback provided on the quality and appropriateness of the curriculum. As optometry is a dynamic profession, it is important that annual curricula reviews be promoted to keep abreast of the latest developments and to benchmark the programmes with others in Africa and globally.

\section{Teaching and learning}

Unfortunately, having the best documented curriculum does not necessarily guarantee the emergence of a high-quality graduate. Despite there being some pockets of QA measures, external examiners at exit level was the most cited response to the question on QA practices in teaching and learning. Healey $^{27}$ reminds us that high quality teaching encourages and stimulates high quality student learning, promotes the traditions and values of the discipline, encourages staff to reflect on teaching styles and strategies and promotes good discipline-based pedagogy. Development of scholarship of teaching and research are important elements through which the discipline ultimately progresses. Hence, new optometry programmes paying specific attention to the scholarship of teaching and learning will strengthen the curriculum delivery and positively impact on student learning.

\section{Academic staff}

The noted absence of formal scholastic training and support for academics in the areas of teaching and research limits their ability to enhance the quality of the academic programme. The notion that because someone is a qualified optometrist, he or she should be able to teach optometry has been challenged in some institutions, where the minimum of a master's degree is promoted as a prerequisite for entry into academia. With the continuing advances in pedagogy in the higher education context, it is advised that institutions consider a mandatory system whereby new lecturers complete a higher education teaching programme and be continually mentored and monitored by academic leadership. By virtue of choosing a career in academia, individuals submit to ongoing engagement in educational and clinical professional development. Academics trained in the scholarship of teaching and learning and demonstrating high levels of knowledge, clinical skills and research competency in biomedical and visual sciences, clinical optometry, public health and ethics should be a common goal.

In the absence of a formal review process, programmes can implement annual course reviews, benchmarking, peer evaluations and other self-regulatory measures to continually improve teaching and learning practices. Measures of teaching and learning could be included into mutually agreed upon key performance areas for lecturers. However, performance monitoring should initially adopt a developmental, rather than punitive, approach to ultimately lead to a fully integrated QA system for teaching and learning.

Lecturer evaluations undertaken in the form of student feedback questionnaires may be adopted by more institutions as they serve as a good yardstick of learning. They additionally provide individual feedback, enabling lecturers to identify and focus on areas of weakness towards improvement. Ramsden ${ }^{28}$ refers to evaluation as 'a way of understanding the effects of our teaching on students' learning'. However, to adequately assess the shortcomings, students must receive feedback, as Taub et al. ${ }^{29}$ suggest that no feedback will lead to students becoming resistant to such exercises in the future and they may provide misleading data. Feedback to students must include what will change and those elements, despite their dissatisfaction, that will remain the same. A system of regular peer review could also be implemented as a means of programme self-evaluation.

\section{Student support}

Only one of the 11 institutions employs a full-time academic development officer providing academic and social support to students within the optometry department. Once students are accepted into the programme, all effort should be made to ensure that they are supported throughout towards exiting as graduates with the knowledge, clinical skills and attitudes needed to serve communities and engage in lifelong learning. Noting that psychosocial factors impact on the success of undergraduate students, ${ }^{30}$ the social and educational background of many students creates challenges that require support programmes. Agar and Knopfmacher ${ }^{31}$ advocate for extensive support programmes to enhance academic performance and improve the overall student experience and throughput rates. In addition to lecturers being sensitive and supportive to students requiring assistance, the model of having a full-time academic and social support person or easily accessible system for students could be adopted. 


\section{Research}

This study exposed the lack of a research ethos across optometry programmes in Africa and an extremely poor scholarly publication rate. Broad-based research capacity building programmes, initiated by the very few established researchers with high publication rates, should be implemented at institutions. New programmes could develop research capacity by academics initially engaging in group research projects and publishing collectively. The need for research that will contribute to African scholarship and provide the empirical evidence to address the vast eye care challenges cannot be overemphasised. Boelen et al. ${ }^{32}$ suggest that research priorities can be developed by engagement with communities to identify future eye health needs, explore health service delivery models and determine programme impact within the communities. The profile of the optometry profession will be enhanced if research output contributes to local, regional and/or national eye health policy in the respective country. Academics are encouraged to engage in research that contributes to technological developments in the fields of clinical optometry, public health and vision sciences. As time was cited as a hindering factor to research engagement, the workloads of academics should be reviewed and sufficient time allocated for research activities.

\section{Community engagement}

Institutions are an integral part of their communities and hence should include the community as a stakeholder to provide input on the curriculum and feedback on the quality of their graduates. To adequately prepare students for the context within which they will work, the Mozambican principle of assigning each student to a family could be reviewed and adopted by other programmes to this end. Community outreach programmes should start in the early years to enrich the understanding of the general disease and social community profiles. To enhance community engagement, Curran and Rourke $^{33}$ suggest strategies that include outreach education preparatory courses, admission and recruitment policies recognising diversity and tuition and scholarship support.

\section{Resources}

The dire lack of resources reported, especially by the new programmes in this study, draws stark attention to the impact of poverty on education institutions and supports the arguments against merely adopting models from wellresourced countries. We are reminded of the declaration by Eshetu and Woldesenbet ${ }^{34}$ that the general health inequalities caused by poverty significantly differ from those caused by living in materially well-off but unequal societies and, accordingly, affect the programme quality to a greater degree. It is thus a challenge for academics in poor nations to try to provide clinical training of a high standard when basic teaching and learning resources and clinical equipment are very limited or unavailable. Academic leaders recognised the enormous financial challenges institutions have, particularly as the numbers of non-fee-paying student's increases. The respective governments and other social partners such as business, the optical industry and donor organisations could be approached to contribute material resources required for quality teaching and research to be a reality.

In undertaking a self-review exercise, the department concerned must identify resource gaps such as lecture or seminar venues with appropriate facilities (seats, data projectors, computers, lighting, screens, boards, etc.), e-learning resources, training laboratories (ophthalmic optics, visual science, clinical techniques, optical dispensing), clinical training facilities and human resources to deliver a quality academic programme. Training of in-house equipment technicians is critical as leaders reported having to wait months for a minor repair because of the lack of local technical expertise. Partnerships with the optical industry to aid with training of in-house technicians and provision of funding or updated optical equipment as part of their corporate social investment programmes must be explored. However, Cancedda et al. $^{35}$ appeal for the funding from development partners to come with fewer restrictions. They suggest that whenever possible, low income countries should also have more direct control of funds. This can be afforded with a requirement of having systems in place to ensure accountability. The authors further cite the Medical Education Training Partnership Initiative and the Rwanda Human Resources for Health Program as good examples of instances where the local government and/or academic institutions were the primary recipients of the funds and were able to select the strategic partners whom they felt were the best fit to address their identified priorities. Hence, an ongoing quality culture requires material resources with adequate numbers of academics administrative and other support staff.

\section{Leadership and governance}

The reported challenge of young inexperienced leadership can be aided by providing training, mentoring and support. In some instances, the new graduate is the only individual available to lead a programme. It is recommended that a regional leadership training programme be developed for the continent to strengthen leadership capacity and support young academics with aspirations to become heads of programmes.

Programmes that are regulated and where standards are monitored externally at a national level provide stakeholder confidence of the quality of graduates exiting from any of the local institutions. It is recommended that in countries in subSaharan Africa where this accreditation system does not currently exist, governments work to create a regulatory framework for optometric education and professional practice. Government involvement is critical as contained in Recommendation 4 of the Kampala Declaration (WHO), ${ }^{36}$ which recommends ' $[g]$ lovernments to devise rigorous accreditation systems for health worker education and training, complemented with health workers and their professional organisations'.

In the absence of governance by external accreditors in most countries participating in this study, new programmes are 
encouraged to, in the interim, develop protocols for implementation of periodic self-review processes, which will begin to introduce a QA culture. Advisory committees, including senior optometrists within the profession, may be invited to perform 'mock audits' and to provide objective feedback. An aspiration could be that the optometry department self-review biannually whilst professional regulatory bodies, in collaboration with community stakeholders, evaluate the programme at least every 5-7 years. The ongoing accreditation of programmes will ultimately lead to stronger optometric education and practice. This notion of continuous accreditation cycles is supported by Blouin and Tekian, ${ }^{37}$ who suggest that accreditation leads medical schools to commit resources to and engage in self-assessment activities that represent best practices of continuous quality improvement (CQI). They further argue that strong CQI orientation leads to high quality education and would serve as a proxy marker for the quality of graduates and possibly for the quality of care they provide. Development of leadership expertise in QA for the continent should ideally be driven by the African Council of Optometry.

\section{Impact}

Quality assurance frameworks are devised to assure competence in teaching, service and research in higher education institutions. However, Akoojee et al. ${ }^{38}$ stress that education quality cannot be situated within politically or ideologically neutral criteria, implying that institutions need to be informed and responsive to health needs in their respective countries. Periodic formal engagements should be undertaken with employers and community organisations to obtain feedback on relevance and impact of training and academic, clinical and core competence of graduates. A recommendation is made for documented evidence of the impact of the programme on eye care policy and services in the respective country (number of graduates produced, quality of education and training, employee feedback, community involvement, essential national health research output and impact on general and eye health policy) to be available.

\section{Conclusion}

Despite QA now being embedded into the discourse of higher education, ${ }^{37}$ optometric education across sub-Saharan Africa has yet to adopt the concept and entrench a continuous quality culture across programmes. This article highlighted the need for institutions to adopt QA policies and principles across entire programmes to meet globally defined quality standards and exposed some gaps in the optometry programmes in sub-Saharan Africa. Programmes can be supported by regional organisations and by the World Council for Optometry through the Legislation, Regulation and Standards Committee. These regional and global bodies could begin to support institutional leadership by developing and disseminating a self-evaluation $Q A$ toolkit to be adapted and utilised within their respective contexts. Hence, a collective effort by all sectors is required to foster a culture of QA in optometric education.

\section{Acknowledgements}

The author would like to acknowledge her supervisors, Prof. J. Loughman and Prof K.S. Naidoo, for their guidance and support throughout my PhD study.

\section{Competing interests}

The author declares that she has no financial or personal relationships that may have inappropriately influenced her in writing this article.

\section{Funding information}

A research study grant was awarded by Irish Aid and its partners to undertake the PhD study.

\section{References}

1. Mishra S. Quality assurance in higher education: An introduction. 2nd ed. Bangalore: National Printing Press; 2007.

2. Van Vught FA, Westerheijden DF. Towards a general model of quality assessment in higher education. The historical roots of quality assessment in higher education. Higher Educ. 1994;28(9):355-371. https://doi.org/10.1007/BF01383722

3. Materu P. Higher education quality assurance in sub-Saharan Africa: Status. 2007. Available from: $\mathrm{http} / / /$ scholar.google.com/scholar?hl=en\&btnG=Search\&q=intitle: Higher+Education+Quality+Assurance+in+Sub-Saharan+Africa\#4

4. Da Dalt L, Callegaro S, Mazzi A, et al. A model of quality assurance and quality improvement for post-graduate medical education in Europe. Med Teach. 2010;32(2):e57-e64. https://doi.org/10.3109/01421590903199734

5. Singh M. Quality assurance in higher education: Which pasts to build on, what futures to contemplate? Quality Higher Educ. 2010;16(2):189-194. https://doi.org/ $10.1080 / 13538322.2010 .485735$

6. Quality Assurance Agency for Higher Education. The UK quality code for highe education: A brief guide. 2012. [cited 2012 Jan 17]. Available from: http://he. macclesfield.ac.uk/

7. Fang HQ. A comparison of learning and teaching quality assurance in Chinese and British Undergraduate Education. Educate. 2010;10(1):19-35.

8. Council for Higher Education (CHE). Towards a framework for quality promotion and capacity development in South African Higher Education. Pretoria: CHE; 2005.

9. Duff T, Hegarty J, Hussey M. Academic quality assurance in Irish Higher Education: Elements of a handbook. Dublin: Blackhall Publishing; 2000.

10. Harvey L, Green D. Defining quality. Assess Eval High Educ. 1993;18(1):9-34 https://doi.org/10.1080/0260293930180102

11. Vroeijenstijn Al. Quality assurance in medical education. Acad Med. 1995 [cited 2016 Oct 20];70(7 Suppl):S59-S67. Available from: http://www.ncbi.nlm.nih.gov/ pubmed/7626161

12. Moloi KC, Motaung RM. Challenges of total quality in education through quality assurance principles in one institution of higher education in South Africa. Med J Soc Sci. 2014;5(1):137-145.

13. Du Toit R, Faal HB, Etya'ale D, et al. Evidence for integrating eye health into primary health care in Africa: A health systems strengthening approach. BMC Health Serv Res. 2013;18:13. https://doi.org/10.1186/1472-6963-13-102

14. Nabwera HM, Purnell S, Bates I. Development of a quality assurance handbook to improve educational courses in Africa. Hum Res Health. 2008;6:28. https://doi org/10.1186/1478-4491-6-28

15. World Federation of Medical Education (WFME). Basic Medical Education. WFME Global Standards for Quality Improvement. New edition [Internet]. 2012 Available from: http://wfme.org/standards/bme/78-new-version-2012-qualityimprovement-in-basic-medicaleducation-english/file

16. Health Professions Council of South Africa. Professional Board for Optometry and Dispensing Opticians Accreditation Standards, 2014.

17. World Council for Optometry (WCO). A global competency-based model of scope of practice in optometry. August 2015

18. Oduntan OA, Mashige KP, Kio FE, Boadi-Kusi SB. Optometric education in Africa. Optom Vis Sci. 2013;91(3):1. https://doi.org/10.1097/OPX.0000000000000153

19. Ogachi O. Internationalization vs regionalization of higher education in East Africa and the challenges of quality assurance and knowledge production. Higher Educ Policy. 2009;22(3):331-347. https://doi.org/10.1057/hep.2009.9

20. Materu P, Nicolas P. Higher education quality assurance in sub Saharan Africa. Library of Congress Cataloging-in-Publication Data. Washington, DC: World Bank; 2007.

21. Mohamedbhai G. Massification in higher education institutions in Africa: Causes, consequences and responses. Int J Afr Higher Educ. 2014 [cited 2016 Oct 24];1(1) Available from: http://ejournals.bc.edu/ojs/index.php/ijahe/article/view/5644

22. Materu PN. Higher education quality assurance in sub-Saharan Africa. The World Bank; 2007 [cited 2016 Oct 24]. Available from: http://elibrary.worldbank.org/ doi/book/10.1596/978-0-8213-7272-2 
23. Strasser RP, Lanphear JH, McCready WG, Topps MH, Hunt DD, Matte MC. Canada's new medical school: The Northern Ontario School of Medicine: Social new medical school: The Northern Ontario School of Medicine: Social 2009;84(10):1459-1464. https://doi.org/10.1097/ACM.0b013e3181b6c5d7

24. Association of Schools and Colleges (ASCO). No date. Optometry Admission Test. [cited n.d.]. Available from: https://www.ada.org/en/oat

25. Romine WL, Miller ME, Knese, SA, Folk WR. Multilevel assessment of middle school students' interest in the health sciences: Development and validation of a new measurement tool. CBE Life Sci Educ. 2016 [cited 2016 Nov 12];15(2):21. Available from: http://www.ncbi.nlm.nih.gov/pubmed/27252297

26. Strasser R, Hogenbirk JC, Minore B, et al. Transforming health professional education through social accountability: Canada's Northern Ontario School of Medicine. Med Teach. 2013;35(6):490-496. https://doi.org/10.3109/0142159X.2013.774334

27. Healey M. Developing the scholarship of teaching in higher education: A disciplinebased approach. Higher Educ Res Dev. 2000;19(2):169-189. https://doi.org/ 10.1080/072943600445637

28. Ramsden P. Learning to teach in higher education. New York: Routledge/Falmer; 2003.

29. Taub A, Birch DA, Auld ME, Lysoby L, Rasar King L. Strengthening quality assurance in health education: Recent milestones and future directions. Health Prom Prac. 2009;10(2):192-200. https://doi.org/10.1177/1524839908329854

30. Petersen I, Louw J, Dumont K. Adjustment to university and academic performance among disadvantaged students in South Africa. Educ Psychol. 2009;29(1):99-115. https://doi.org/10.1080/01443410802521066
31. Agar DL, Knopfmacher N. The learning and study strategies inventory: A South African application. Higher Educ. 1995;30(1):115-126. https://doi.org/10.1007/ BF01384056

32. Boelen C, Dharamsi S, Gibbs T. The social accountability of medical schools and its indicators. Educ Health. 2012;25(3):180-194. https://doi.org/10.4103/13576283.109785

33. Curran V, Rourke J. The role of medical education in the recruitment and retention of rural physicians. Med Teach. 2004;26(3):265-72. https://doi.org/10.1080/ 0142159042000192055

34. Eshetu EB, Woldesenbet SA. Are there particular social determinants of health for the world's poorest countries? Afr Health Sci. 11(1):108-115.

35. Cancedda C, Farmer PE, Kerry V, et al. Maximizing the impact of training initiatives for health professionals in low-income countries: Frameworks, challenges, and best practices. PLoS Med. 2015;12(6):e1001840. [cited n.d. ]. Available from: http://journals.plos.org/plosmedicine/article/asset?id=10.1371/journal. pmed.1001840.PDF

36. World Health Organization. The Kampala declaration and agenda for Global Action. Geneva: WHO Press' 2008.

37. Blouin D, Tekian A. Accreditation of medical education programs: Moving from student outcomes to continuous quality improvement measures. Acad Med. 2018;93(3):377-383. https://doi.org/10.1097/ACM.0000000000001835

38. Akoojee S, Nkomo S, Nkomo S. Access and quality in South African higher education: The twin challenges of transformation. SAJHE. 2008;21(3):385-399. https://doi.org/10.4314/sajhe.v21i3.25712 